Zhai, Z. and Chen, Q. 2004. "Numerical determination and treatment of convective heat transfer coefficient in the coupled building energy and CFD simulation,” Building and Environment, 36(8), 1000-1009.

\title{
NUMERICAL DETERMINATION AND TREATMENT OF CONVECTIVE HEAT TRANSFER COEFFICIENT IN THE COUPLED BUILDING ENERGY AND CFD SIMULATION
}

\author{
Zhiqiang Zhai* \\ Department of Civil, Environmental and Architectural Engineering, University of Colorado, \\ UCB 428, ECOT 441, Boulder, CO 80309-0428, USA \\ Qingyan (Yan) Chen \\ Ray W. Herrick Laboratories, School of Mechanical Engineering, Purdue University, \\ 585 Purdue Mall, West Lafayette, IN 47907-2088, USA
}

\begin{abstract}
The integration of building Energy Simulation (ES) and Computational Fluid Dynamics (CFD) programs eliminates many assumptions employed in the separate applications, resulting in more accurate predictions of building performance. This paper discusses the methods used to determine convective heat transfer on interior surfaces of building envelope, which is the key linkage between ES with CFD programs. The study found that the size of the first grid near a wall in CFD is crucial for the correct prediction of the convective heat. A finer grid resolution in CFD does not always lead to a more accurate solution when using zero-equation turbulence models. Through numerical experiments, the paper suggests a universal first grid size at $0.005 \mathrm{~m}$ for natural convection room airflows and $0.1 \mathrm{~m}$ for forced convection indoor airflows. The investigation also found that negative convective heat transfer coefficients may cause divergence and instability of the coupled simulation.
\end{abstract}

KEYWORDS: Convective Heat Transfer, Energy Simulation, CFD, Coupling

\section{INTRODUCTION}

A building energy simulation (ES) program predicts building thermal performance, while a computational fluid dynamics (CFD) program calculates detailed airflow characters. Both of them are important tools for building performance evaluation and have been widely used in building and system design practices. Many literatures on this topic are available, such as those by Clarke [1], Chen [2], Martin [3], Chen and Srebic [4] etc. The coupling of ES and CFD can take full advantages of the individual programs and produce more accurate and complete results, because they can provide complementary boundary conditions to each other. For example, ES can provide interior surface temperatures of building envelopes and heating/cooling load to CFD as boundary conditions while CFD can determine accurate surface convective heat fluxes for ES. The benefits of the integration have been discussed in many previous studies, such as, by Clarke [5], Nielsen and Tryggvason [6], Srebric et al. [7], Beausoleil-Morrison et al. [8], and Zhai et al. [9].

In a coupled simulation, ES calculates the heat conduction through building envelopes and CFD determines air movement in an indoor space. The convective heat transfer on interior surfaces of building envelope is the most important linkage to couple these two programs [9]. In the coupling, CFD provides ES convective heat transfer on each enclosure surface. The convective heat transfer calculated by CFD is highly sensitive to the numerical methods and turbulence models employed in CFD. This study analyzes the effect of the size of the first grid to a wall used in CFD on the heat transfer and examines how turbulence models determine the convective heat transfer. In addition, with traditional definition of convective heat transfer coefficient, which is based on the temperature difference of an interior surface and room air, the coefficient value can be negative. The impact of negative coefficient on the coupled simulation is another subject of this study.

\section{FACTORS TO NUMERICAL SOLUTION OF CONVECTIVE HEAT TRANSFER}

CFD discretizes the computational domain into many grid cells and solves the governing conservation equations of flow on these grid cells. As shown in Figure 1(a), CFD calculates convective heat transfer from a rigid surface through:

$$
\begin{aligned}
& \mathrm{Q}=\mathrm{hA}\left(\mathrm{T}_{\text {surface }}-\mathrm{T}_{1}\right) \\
& \mathrm{h}=\mathrm{C}_{\mathrm{p}} \frac{\rho\left(v_{\mathrm{t}}+v\right)}{\operatorname{Pr}} \frac{1}{\mathrm{D}}
\end{aligned}
$$

where $\mathrm{h}$ is convective heat transfer coefficient, $\mathrm{A}$ is surface area, $\mathrm{T}_{\text {surface }}$ is surface temperature, $\mathrm{T}_{1}$ is air temperature at the first grid node that is at a normal distance of D to the surface, $\mathrm{C}_{\mathrm{p}}$ is the specific heat of air, $\mathrm{Pr}$

\footnotetext{
*Corresponding author, email: john.zhai@colorado.edu, fax: 303-4927317
} 
is Prandtl number, $\rho$ is air density, $v_{t}$ is turbulence viscosity determined by turbulence models at the first grid node, and $v$ is the molecular viscosity of air. According to Equations (1) and (2), the convective heat transfer is determined by the convective heat transfer coefficient and temperature difference between the surface and air at the first grid node, and the convective heat transfer coefficient is determined by effective viscosity of air (turbulence viscosity plus molecular viscosity) at the first grid node. In order to obtain accurate surface convective heat transfer, it is important to find its relationship with the $\mathrm{D}$ and turbulence model.

Since the size of the first grids in CFD can be adjusted according to the resolution requirement, the convective heat calculated in this manner could be grid-dependent. Another method is to use a prescribed distance, $\mathrm{D}_{2}$, to a wall surface and calculate convective heat transfer based on the air temperature and effective viscosity there, as illustrated in Figure 1(b). Since the $\mathrm{D}_{2}$ is a prescribed value, this method would eliminate the grid dependence problem.

However, the convective heat transfer calculated with the second method could be different from that calculated based on the information at the first grid node. For example, if assuming laminar flow and $\mathrm{D}_{2}=2 \mathrm{D}$, the same heat transfer would require $T_{\text {surface }}-T_{2}=2\left(T_{\text {surface }}-T_{1}\right)$. This implies a linear air temperature profile in the region, which is true only at the very close vicinity of the surface for laminar flow. Such a condition is difficult to meet for most indoor airflows.

Therefore, the calculation of convective heat transfer should use the first method. The question now is how to avoid the grid dependence problem or what the size of first grids should be for the correct prediction of convective heat transfer. CFD theory indicates that finer grids provide more accurate results [10]. This may not be true when using simple turbulence models. This paper discusses the grid dependence problem in the following sections by using laminar and turbulent flows over a flat plate as examples.

\section{CONVECTIVE HEAT TRANSFER IN LAMINAR FLOWS}

First this investigation considers a laminar flow of forced convection along a horizontal plate and that of natural convection along a vertical plate, as illustrated in Figure 2. The convective heat transfer computed by CFD is compared with the analytical and empirical solutions to identify the impact of the size of first grid on the heat transfer.

The convective heat transfer through the thermal boundary layer of the plate is:

$$
\mathrm{q}_{\text {surface }}=-\left.\mathrm{k} \frac{\partial \mathrm{T}}{\partial \mathrm{y}}\right|_{\mathrm{y}=0}=\mathrm{h}\left(\mathrm{T}_{\text {surface }}-\mathrm{T}_{\infty}\right)
$$

where $\mathrm{k}$ is the fluid conductivity, $\mathrm{T}_{\text {surface }}$ is the plate surface temperature, $\mathrm{T}_{\infty}$ is the temperature of the free stream outside of the thermal boundary layer. Equation (3) shows that the heat conduction is the same as the convective heat transfer, because there is no fluid motion in the direction of heat transfer.

\section{(1) Forced Convection}

The exact solution of the laminar plate flow of forced convection is [11]

$$
\begin{aligned}
& \frac{U}{U_{\infty}}=\frac{T_{\text {surface }}-T}{T_{\text {surface }}-T_{\infty}}=1-\frac{T-T_{\infty}}{T_{\text {surface }}-T_{\infty}} \\
& \mathrm{q}_{\text {surface }}=-k \frac{\partial T}{\partial y}=-\rho C_{p} \frac{v}{\operatorname{Pr}} \frac{\partial T}{\partial y}=\frac{3}{2} k \frac{T_{\text {surface }}-T_{\infty}}{\delta_{t}}
\end{aligned}
$$

where $\delta_{\mathrm{t}}$ is the thickness of thermal boundary layer and $\mathrm{k}=\rho \mathrm{C}_{\mathrm{p}} \mathrm{v} / \mathrm{Pr}$.

The analytical solution of the boundary layer equations shows $\delta=\delta_{\mathrm{t}}$ when $\operatorname{Pr}=1$, where $\delta$ is the thickness of velocity boundary layer. The exact solution of the boundary layer equations produces [11]

$$
\delta=4.92 \mathrm{x} / \sqrt{\operatorname{Re}_{\mathrm{x}}}
$$

where $\operatorname{Re}_{x}=\frac{U_{\infty} x}{v}$ is the Reynolds number of plate flow. For example, if the velocity is $0.1 \mathrm{~m} / \mathrm{s}$ over a $5 \mathrm{~m}$ long plate, 


$$
\operatorname{Re}_{\mathrm{L} / 2}=\frac{\mathrm{UL} / 2}{v}=\frac{0.1 \times 2.5}{1.5 \times 10^{-5}}=1.7 \times 10^{4}
$$

the $\delta_{\mathrm{t}}$ at the middle length of the plate is $\delta_{\mathrm{t}}=\delta \approx 0.09 \mathrm{~m}$.

A CFD program would calculate the convective heat transfer from the plate as

$$
\mathrm{q}_{\mathrm{CFD}}=-\rho \mathrm{C}_{\mathrm{p}} \frac{v}{\operatorname{Pr}} \frac{\mathrm{T}_{\mathrm{D}}-\mathrm{T}_{\text {surface }}}{\mathrm{D}}=\mathrm{k} \frac{\mathrm{T}_{\text {surface }}-\mathrm{T}_{\mathrm{D}}}{\mathrm{D}}
$$

where $\mathrm{D}$ is the normal distance from the center of the first grid cell to the surface (half of the cell size) and $T_{D}$ is the air temperature at cell center. In order to analyze possible errors associated with grid sizes, this study considers two different grid sizes: $\mathrm{D}$ is smaller than $\delta_{\mathrm{t}}$ and $\mathrm{D}$ is larger than $\delta_{\mathrm{t}}$.

- $\mathrm{D}<\delta_{\mathrm{t}}$

When $\mathrm{D}$ is smaller than $\delta_{\mathrm{t}}$, the possible numerical error is

$$
\Delta \mathrm{q}=\mathrm{q}_{\mathrm{CFD}}-\mathrm{q}_{\text {surface }}=-\rho \mathrm{C}_{\mathrm{p}} \frac{\nu}{\operatorname{Pr}} \frac{\mathrm{T}_{\mathrm{D}}-\mathrm{T}_{\text {surface }}}{\mathrm{D}}-\mathrm{q}_{\text {surface }}=\mathrm{k} \frac{\mathrm{T}_{\text {surface }}-\mathrm{T}_{\mathrm{D}}}{\mathrm{D}}-\mathrm{k} \frac{\mathrm{T}_{\text {surface }}-\mathrm{T}_{\infty}}{\frac{2}{3} \delta_{\mathrm{t}}}
$$

Because the temperature profile in the thermal boundary can be approximated as [11]

$$
\frac{\mathrm{T}_{\mathrm{D}}-\mathrm{T}_{\text {surface }}}{\mathrm{T}_{\infty}-\mathrm{T}_{\text {surface }}}=\frac{3}{2} \frac{\mathrm{D}}{\delta_{\mathrm{t}}}-\frac{1}{2}\left(\frac{\mathrm{D}}{\delta_{\mathrm{t}}}\right)^{3}
$$

the relative error of convective heat transfer due to $\mathrm{D}$ then becomes

$$
\frac{\Delta \mathrm{q}}{\mathrm{k}\left(\mathrm{T}_{\text {surface }}-\mathrm{T}_{\infty}\right)}=\frac{\mathrm{T}_{\text {surface }}-\mathrm{T}_{\mathrm{D}}}{\left(\mathrm{T}_{\text {surface }}-\mathrm{T}_{\infty}\right) \mathrm{D}}-\frac{\mathrm{T}_{\text {surface }}-\mathrm{T}_{\infty}}{\left(\mathrm{T}_{\text {surface }}-\mathrm{T}_{\infty}\right) \frac{2}{3} \delta_{\mathrm{t}}}=\left(\frac{3}{2} \frac{\mathrm{D}}{\delta_{\mathrm{t}}}-\frac{1}{2}\left(\frac{\mathrm{D}}{\delta_{\mathrm{t}}}\right)^{3}\right) \frac{1}{\mathrm{D}}-\frac{1}{\frac{2}{3} \delta_{\mathrm{t}}}=-\frac{1}{2} \frac{\mathrm{D}^{2}}{\delta_{\mathrm{t}}^{3}}
$$

Equation (11) verifies that the smaller the D the more accurate the calculated convective heat transfer. The error of convective heat transfer due to $\mathrm{D}$ is on the order of $\mathrm{O}\left(\mathrm{D}^{2}\right)$ for this case.

- $\mathrm{D} \geq \delta_{\mathrm{t}}$

The same analysis can be conducted when $\mathrm{D}$ is equal to or larger than $\delta_{t}$, where $\mathrm{T}_{\mathrm{D}}=\mathrm{T}_{\infty}$. Then,

$$
\frac{\Delta \mathrm{q}}{\mathrm{k}\left(\mathrm{T}_{\text {surface }}-\mathrm{T}_{\infty}\right)}=\frac{1}{\mathrm{D}}-\frac{1}{\frac{2}{3} \delta_{\mathrm{t}}}=\frac{1}{\mathrm{D}}-\frac{3}{2 \delta_{\mathrm{t}}}
$$

Equation (12) shows that the minimum error of the calculated heat flux is one-third of the analytical solution in Equation (5) as D equals $\delta_{t}$. The convective heat transfer calculated will deviate significantly from the actual solution if the size of first grids is unreasonably large.

\section{(2) Natural Convection}

For the natural convection case, the analytical solution shows [11]

$$
\delta_{\mathrm{t}}^{4}=\frac{240\left(\frac{20}{21}+\operatorname{Pr}\right)}{\operatorname{Pr}^{2} \frac{\mathrm{g} \beta\left|\mathrm{T}_{\text {surface }}-\mathrm{T}_{\infty}\right|}{v^{2}}} \mathrm{x}
$$

With this equation, one can roughly estimate the scale of $\delta_{t}$ due to natural convection in the middle of a $3 \mathrm{~m}$ vertical wall at $40^{\circ} \mathrm{C}$ and room air temperature at $25^{\circ} \mathrm{C}$ to be $0.024 \mathrm{~m}$.

The analytical solution of the convective heat transfer for natural convection is [11] 


$$
\mathrm{q}_{\text {surface }}=2 \frac{\mathrm{k}\left(\mathrm{T}_{\text {surface }}-\mathrm{T}_{\infty}\right)}{\delta_{\mathrm{t}}}
$$

while the CFD equation for natural convection is the same as Equation (8) for forced convection.

Therefore,

$$
\frac{\Delta \mathrm{q}}{\mathrm{k}\left(\mathrm{T}_{\text {surface }}-\mathrm{T}_{\infty}\right)}=\frac{\mathrm{T}_{\text {surface }}-\mathrm{T}_{\mathrm{D}}}{\left(\mathrm{T}_{\text {surface }}-\mathrm{T}_{\infty}\right) \mathrm{D}}-\frac{2}{\delta_{\mathrm{t}}}
$$

- $\mathrm{D}<\delta_{\mathrm{t}}$

When $\mathrm{D}$ is smaller than $\delta_{\mathrm{t}}$,

$$
\begin{gathered}
\frac{\mathrm{T}_{\text {surface }}-\mathrm{T}_{\mathrm{D}}}{\mathrm{T}_{\text {surface }}-\mathrm{T}_{\infty}}=1-\frac{\mathrm{T}_{\mathrm{D}}-\mathrm{T}_{\infty}}{\mathrm{T}_{\text {surface }}-\mathrm{T}_{\infty}}=1-\left(1-\frac{\mathrm{D}}{\delta_{\mathrm{t}}}\right)^{2} \\
\frac{\Delta \mathrm{q}}{\mathrm{k}\left(\mathrm{T}_{\text {surface }}-\mathrm{T}_{\infty}\right)}=\frac{\mathrm{T}_{\text {surface }}-\mathrm{T}_{\mathrm{D}}}{\left(\mathrm{T}_{\text {surface }}-\mathrm{T}_{\infty}\right) \mathrm{D}}-\frac{2}{\delta_{\mathrm{t}}}=\frac{1}{\mathrm{D}}\left(1-\left(1-\frac{\mathrm{D}}{\delta_{\mathrm{t}}}\right)^{2}\right)-\frac{2}{\delta_{\mathrm{t}}}=\frac{1}{\mathrm{D}}\left(\frac{2 \mathrm{D}}{\delta_{\mathrm{t}}}-\frac{\mathrm{D}^{2}}{\delta_{\mathrm{t}}^{2}}\right)-\frac{2}{\delta_{\mathrm{t}}}=-\frac{\mathrm{D}}{\delta_{\mathrm{t}}^{2}}
\end{gathered}
$$

Hence, the smaller the size of first grids, the better the accuracy. The calculation error of the convective heat transfer due to the size of first grids (2D) is on the order of $\mathrm{O}(\mathrm{D})$ for natural convection.

- $\mathrm{D} \geq \delta_{\mathrm{t}}$

Since $\mathrm{T}_{\mathrm{D}}=\mathrm{T}_{\infty}$ when $\mathrm{D} \geq \delta_{t}$, Equation (15) becomes

$$
\frac{\Delta \mathrm{q}}{\mathrm{k}\left(\mathrm{T}_{\text {surface }}-\mathrm{T}_{\infty}\right)}=\frac{1}{\mathrm{D}}-\frac{2}{\delta_{\mathrm{t}}}
$$

The equation is very similar to Equation (12) for forced convection, except that the analytical heat flux is different.

\section{CONVECTIVE HEAT TRANSFER IN TURBULENT FLOWS}

The study on laminar flows verifies that finer grid distribution provides more accurate solutions. However, most indoor airflows are turbulent. The analysis for turbulent flows is more complicated than that for laminar flow, because the accuracy of convective heat transfer predicted in turbulent flows depends on both the size of first grids and turbulence model used. This study has examed the accuracy by using three zero-equation turbulence models and different grid resolutions for a forced convection flow along a plate. The zero-equation turbulence models are frequently used in the CFD simulation for building design due to their simpleness and efficiency. The three zero-equation turbulence models tested here are:

(1) Constant viscosity model:

$$
v_{\mathrm{t}}=100 \mathrm{v}
$$

(2) Xu's zero-equation model [12]:

$$
v_{\mathrm{t}}=0.03874\left|\mathrm{U}_{\mathrm{D}}\right| 1
$$

where 1 is the normal distance to the surface and $U_{D}$ is the airflow speed at this location.

(3) Prandtl's zero-equation model [13]:

$$
v_{t}=2 \kappa^{2} y^{2}\left|\frac{\partial U}{\partial y}\right|
$$

where $\kappa=0.41$ and $\mathrm{y}$ is the distance to the surface.

The convective heat transfer in turbulent flows is related to turbulence as defined by 


$$
\mathrm{q}=-\left.\rho \mathrm{C}_{\mathrm{p}}\left(\frac{v}{\operatorname{Pr}}+\frac{v_{\mathrm{t}}}{\operatorname{Pr}_{\mathrm{t}}}\right) \frac{\partial \mathrm{T}}{\partial \mathrm{y}}\right|_{\mathrm{y}=0}=\mathrm{h}\left(\mathrm{T}_{\text {surface }}-\mathrm{T}_{\infty}\right)
$$

where $v_{t}$ is turbulence eddy viscosity and T represents Reynolds-averaged temperature. In Equation (22), $v_{t}>>v$ for the flow region away from walls, and $v_{t}<<v$ for the near wall region, which is called viscous sub-layer. It is obvious that if the first grid is located in the viscous sub-layer, the relationship between the convective heat transfer predicted and the size of first grids is similar to that for laminar flow. The heat transfer computed does not directly depend on the turbulence model, although the turbulence model does influence the velocity and temperature profiles. According to the empirical equation [11],

$$
\delta_{\text {turbulence }}=0.057[(\mathrm{n}+1)(\mathrm{n}+2) / \mathrm{n}]^{0.8} \operatorname{Re}_{\mathrm{x}}^{-0.2} \mathrm{x}
$$

where $\mathrm{n}=7$ for a common velocity profile in the boundary layer, $\delta_{\text {turbulence }}$ for a forced convection with a velocity $0.1 \mathrm{~m} / \mathrm{s}$ over a $5 \mathrm{~m}$ long plate is

$$
\delta_{\text {turbulence }}=0.13 \mathrm{~m}
$$

and $\delta_{\text {sub-layer }} \approx 0.15 \sim 0.2 \delta_{\text {turbulence }}=0.02 \sim 0.03 \mathrm{~m}$. When the velocity is increased to $1 \mathrm{~m} / \mathrm{s}, \delta_{\text {turbulence }}$ and $\delta_{\text {sub-layer }}$ are reduced to $0.08 \mathrm{~m}$ and $0.01 \sim 0.02 \mathrm{~m}$, respectively.

The empirical solution for the turbulent plate flow and heat transfer gives [11]

$$
\mathrm{Nu}_{\mathrm{x}}=0.0296 \operatorname{Re}_{\mathrm{x}}^{0.8} \operatorname{Pr}^{1 / 3}=\mathrm{hx} / \mathrm{k}
$$

Considering the heat transfer in the middle of the plate with a velocity of $0.1 \mathrm{~m} / \mathrm{s}$,

$$
\mathrm{Nu}_{\mathrm{L} / 2}=0.0296 \operatorname{Re}_{\mathrm{L} / 2}^{0.8} \operatorname{Pr}^{1 / 3}=0.0296 \times\left(\frac{0.1 \times 2.5}{1.5 \times 10^{-5}}\right)^{0.8} \times 1^{1 / 3}=70.6=\mathrm{hL} / 2 \mathrm{k}
$$

As a result,

$$
\mathrm{q}_{\text {surfce }}=\mathrm{h}\left(\mathrm{T}_{\text {surface }}-\mathrm{T}_{\infty}\right)=28.2 \mathrm{k}\left(\mathrm{T}_{\text {surface }}-\mathrm{T}_{\infty}\right)
$$

On the other hand, with the assumption of $\mathrm{Pr}_{t}=\mathrm{Pr}$, a CFD program would calculate the heat transfer as,

$$
\mathrm{q}_{\mathrm{CFD}}=-\left.\rho \mathrm{C}_{\mathrm{p}}\left(\frac{v}{\operatorname{Pr}}+\frac{v_{t}}{\operatorname{Pr}_{\mathrm{t}}}\right) \frac{\partial \mathrm{T}}{\partial \mathrm{y}}\right|_{\mathrm{y}=0}=-\rho \mathrm{C}_{\mathrm{p}} \frac{v+v_{\mathrm{t}}}{\operatorname{Pr}} \frac{\mathrm{T}_{\mathrm{D}}-\mathrm{T}_{\text {surface }}}{\mathrm{D}}=-\mathrm{k} \frac{v+v_{\mathrm{t}}}{\mathrm{v}} \frac{\mathrm{T}_{\mathrm{D}}-\mathrm{T}_{\text {surface }}}{\mathrm{D}}
$$

- $\quad \mathrm{D} \geq \delta_{\mathrm{t}}$

Since $\mathrm{T}_{\mathrm{D}}=\mathrm{T}_{\infty}$ as $\mathrm{D} \geq \delta_{\mathrm{t}}$,

$$
\frac{\Delta \mathrm{q}}{\mathrm{k}\left(\mathrm{T}_{\text {surface }}-\mathrm{T}_{\infty}\right)}=\frac{\mathrm{q}_{\mathrm{CFD}}-\mathrm{q}_{\text {surface }}}{\mathrm{k}\left(\mathrm{T}_{\text {surface }}-\mathrm{T}_{\infty}\right)}=\frac{v+\mathrm{v}_{\mathrm{t}}}{\mathrm{v}} \frac{1}{\mathrm{D}}-28.2
$$

With constant viscosity model:

$$
\frac{\Delta \mathrm{q}}{\mathrm{k}\left(\mathrm{T}_{\text {surface }}-\mathrm{T}_{\infty}\right)}=\frac{v+v_{\mathrm{t}}}{v} \frac{1}{\mathrm{D}}-28.2=\frac{101}{\mathrm{D}}-28.2
$$

With Xu's zero-equation model:

$$
\frac{\Delta \mathrm{q}}{\mathrm{k}\left(\mathrm{T}_{\text {surface }}-\mathrm{T}_{\infty}\right)}=\frac{v+v_{\mathrm{t}}}{v} \frac{1}{\mathrm{D}}-28.2 \approx \frac{v_{\mathrm{t}}}{v} \frac{1}{\mathrm{D}}-28.2=230
$$

With Prandtl's zero-equation model:

$$
\frac{\Delta \mathrm{q}}{\mathrm{k}\left(\mathrm{T}_{\text {surface }}-\mathrm{T}_{\infty}\right)}=\frac{v+v_{\mathrm{t}}}{v} \frac{1}{\mathrm{D}}-28.2 \approx \frac{v_{\mathrm{t}}}{v} \frac{1}{\mathrm{D}}-28.2=2213
$$

- $\mathrm{D}<\delta_{\mathrm{t}}$ 
The temperature and velocity profiles in the boundary layer are approximated as [11]

$$
\frac{\mathrm{T}-\mathrm{T}_{\text {surface }}}{\mathrm{T}_{\infty}-\mathrm{T}_{\text {surface }}}=\frac{\mathrm{U}}{\mathrm{U}_{\infty}}=\left(\frac{\mathrm{y}}{\delta}\right)^{1 / \mathrm{n}}
$$

Hence,

$$
\frac{\mathrm{T}_{\mathrm{D}}-\mathrm{T}_{\text {surface }}}{\mathrm{T}_{\infty}-\mathrm{T}_{\text {surface }}}=\frac{\mathrm{U}_{\mathrm{D}}}{\mathrm{U}_{\infty}}=\left(\frac{\mathrm{D}}{\delta}\right)^{1 / \mathrm{n}}
$$

and

$$
\begin{aligned}
\mathrm{q}_{\mathrm{CFD}} & =-\mathrm{k} \frac{v+v_{t}}{v} \frac{\mathrm{T}_{\mathrm{D}}-\mathrm{T}_{\text {surface }}}{\mathrm{D}} \\
& =-\mathrm{k} \frac{v+v_{\mathrm{t}}}{v} \frac{\mathrm{T}_{\infty}-\mathrm{T}_{\text {surface }}}{\mathrm{D}}\left(\frac{\mathrm{D}}{\delta}\right)^{1 / \mathrm{n}}
\end{aligned}
$$

With constant viscosity model:

$$
\frac{\Delta \mathrm{q}}{\mathrm{k}\left(\mathrm{T}_{\text {surface }}-\mathrm{T}_{\infty}\right)}=\frac{v+v_{\mathrm{t}}}{v}\left(\frac{\mathrm{D}}{\delta}\right)^{1 / \mathrm{n}} \frac{1}{\mathrm{D}}-28.2=\frac{101}{\mathrm{D}^{1-1 / \mathrm{n}} \delta^{1 / \mathrm{n}}}-28.2
$$

With Xu's zero-equation model:

$$
\frac{\Delta \mathrm{q}}{\mathrm{k}\left(\mathrm{T}_{\text {surface }}-\mathrm{T}_{\infty}\right)}=\frac{v+v_{\mathrm{t}}}{v}\left(\frac{\mathrm{D}}{\delta}\right)^{1 / \mathrm{n}} \frac{1}{\mathrm{D}}-28.2 \approx \frac{0.03874 \mathrm{U}_{\infty}}{v}\left(\frac{\mathrm{D}}{\delta}\right)^{2 / \mathrm{n}}-28.2=258\left(\frac{\mathrm{D}}{\delta}\right)^{2 / \mathrm{n}}-28.2
$$

With Prandtl's zero-equation model:

$$
\frac{\Delta \mathrm{q}}{\mathrm{k}\left(\mathrm{T}_{\text {surface }}-\mathrm{T}_{\infty}\right)}=\frac{v+v_{\mathrm{t}}}{v}\left(\frac{\mathrm{D}}{\delta}\right)^{1 / \mathrm{n}} \frac{1}{\mathrm{D}}-28.2 \approx \frac{2 \kappa^{2} \mathrm{U}_{\infty}}{v}\left(\frac{\mathrm{D}}{\delta}\right)^{2 / \mathrm{n}}-28.2=2241\left(\frac{\mathrm{D}}{\delta}\right)^{2 / \mathrm{n}}-28.2
$$

Equations (30)-(32) and (36)-(38) can be illustrated as Figure 3 by using the common velocity profile of $n=7$ and $\delta=0.13 \mathrm{~m}$.

Figure 3 indicates that:

(1) The use of small first grid with the constant viscosity turbulence model would increase the error in predicting the heat flux. A large first grid seems better than a small one.

(2) The error in predicting the heat flux increases as the grid resolution decreases when the other two zeroequation models are used. A finer grid solution is preferred with the two zero-equation models.

Further analysis of Equation (37) indicates that $\mathrm{q}_{C F D}=\mathrm{q}_{\text {surface }}$ only when $\mathrm{D} / \delta=0.0004$. In fact, under this condition, the first grid falls into the viscous sub-layer $\left(\delta_{\text {sub-layer }} / \delta=0.15 \sim 0.2\right)$. In other words, the first grid should be placed in the sub-layer so as to obtain the correct heat flux. Since $v_{t}<<v$ in the sub-layer, Equation (35) can be re-arranged

$$
\begin{aligned}
& \mathrm{q}_{\mathrm{CFD}}=-\mathrm{k} \frac{v+v_{\mathrm{t}}}{\mathrm{v}} \frac{\mathrm{T}_{\infty}-\mathrm{T}_{\text {surface }}}{\mathrm{D}}\left(\frac{\mathrm{D}}{\delta}\right)^{1 / \mathrm{n}} \approx-\mathrm{k} \frac{\mathrm{T}_{\infty}-\mathrm{T}_{\text {surface }}}{\mathrm{D}}\left(\frac{\mathrm{D}}{\delta}\right)^{1 / \mathrm{n}} \\
& \frac{\Delta \mathrm{q}}{\mathrm{k}\left(\mathrm{T}_{\text {surface }}-\mathrm{T}_{\infty}\right)}=\left(\frac{\mathrm{D}}{\delta}\right)^{1 / \mathrm{n}} \frac{1}{\mathrm{D}}-28.2
\end{aligned}
$$

To achieve $\Delta \mathrm{q}=0$, D should be $0.03 \mathrm{~m}$ if $\mathrm{n}=7$ and $\delta=0.13 \mathrm{~m}$. The value is obtained based on the simple plate flow. Real indoor airflows are more complicated. Usually, the momentum and thermal boundary layer in room airflows are thicker than those in the plate flow. The simulation experience from the literatures (e.g. [14]) indicates that $\mathrm{D}=0.05 \mathrm{~m}$ is a good value for most indoor airflows. The following section attempts to validate this value through two case studies by using Xu's zero-equation turbulence model. 


\section{NUMERICAL EXPERIMENTS FOR TWO TYPICAL ROOM AIRFLOWS}

\section{(1) Natural Convection in a Room with an Aspect Ratio of 2.5:7.9}

In order to define a reasonable CFD grid for room airflows, this study first models a natural convection flow in a full-size room as shown in Figure 4. The room was with a hot wall on one end and a cold wall on its opposite. The room was used by Olsen et al. [15] to measure flow and heat transfer. Olson also used a 1:5.5 scale physical model containing R114 gas. The small-scale model was geometrically similar, had the same Reyleigh number, and had the same dimensionless side wall temperature as the full-scale room. The measurement found a good agreement between the full-scale room and the scale model in flow patterns, velocity, temperature distributions, and heat transfer. This study is particularly interested in the convective heat transfer at the hot and cold walls and compares both full-scale and model experimental results with the computed results.

Figure 5 presents the convective heat transfer at the hot and cold walls for both the measurement and simulation where Nusselt number is plotted as a function of Reyleigh number. Also included in the figure is the correlation from Bohn et al. [16], $\mathrm{Nu}=0.31 \mathrm{Ra}^{1 / 4}$, for enclosure flows. The $\mathrm{Nu}$ and $\mathrm{Ra}$ number are based on the temperature difference between the hot and cold walls. The experimental uncertainty is approximately 10 percent for the scale model and 30 percent for the full scale room. The results show that the simulations with the first grid size of $0.002-0.005 \mathrm{~m}$ agree very well with the data, exhibiting the expected trend of increasing $\mathrm{Nu}$ with $\mathrm{Ra}$. The other first grid sizes produce the solutions that are more deviated from the measurements, as illustrated in Figure 6. Note that finer grids do not give more accurate results with the zero-equation model as analyzed. Figure 5 and 6 indicate that the first grid size at $0.005 \mathrm{~m}$ is reasonably good for the indoor natural convection cases.

\section{(2) Forced Convection in a Room with an Aspect Ratio of 5.5:3.7:3.4}

The study further investigates a forced convection flow in an experimental chamber with the side-wall jet [17]. The configuration of the experimental facility is shown in Figure 7. The simulation uses three different grid densities: fine grid $(66 \times 51 \times 45=151,470$ cells $)$ has the first grid size at $0.05 \mathrm{~m}$ to wall; moderate grid $(44 \times 34 \times 30$ $=44,880$ cells $)$ has the first grid at $0.1 \mathrm{~m}$; and coarse grid $(22 \times 17 \times 15=5,610$ cells $)$ has the first grid at $0.2 \mathrm{~m}$. The area-averaged heat fluxes at the room enclosures are then calculated and compared with the measured data, as presented in Figure 8.

The results show that the simulation with the first grid size at $0.05-0.1 \mathrm{~m}$ can provide reasonable solutions for such a forced-convection flow. This conclusion confirms that by Chen [14] who indicated that the first grid size at $0.1 \mathrm{~m}$ is a good value for most indoor airflows.

\section{NEGATIVE h VERSUS CONVERGENCE AND STABILITY OF ES}

ES and CFD programs can exchange the convective heat information on envelope interior surfaces through different methods. Zhai et al. [18] enumerated the possible data exchange methods and comparatively studied each of them through theoretical analysis and numerical experiment. According to the study, the fastest and most robust method to exchange convective heat between ES and CFD is that ES provides interior surface temperatures in a room to CFD while CFD returns the convective heat transfer coefficients $h$ and the air temperatures $T_{D}$ near the surfaces to ES. In order to minimize the modifications in ES programs that use the traditional definition of convection coefficient $\mathrm{h}$ based on the temperature difference of an interior surface and room air, a corrected convective heat transfer coefficients, $h_{\text {corrected, }}$, rather than $h$ and $T_{D}$, can be calculated from CFD results and used in ES. The $\mathrm{h}_{\text {corrected }}$ is calculated in CFD through:

$$
\mathrm{h}_{\text {corrected }}=\mathrm{hA}\left(\mathrm{T}_{\text {surface }}-\mathrm{T}_{\mathrm{D}}\right) / \mathrm{A}\left(\mathrm{T}_{\text {surface }}-\mathrm{T}_{\text {room }}\right)
$$

The $\mathrm{h}$, calculated in CFD based on the flow viscosity (Equation (2)), is always positive. However, $\mathrm{h}_{\text {corrected }}$ can be negative in some particular cases.

Figure 9 illustrates such an example in a room with displacement ventilation. If assuming $\mathrm{h}=4 \mathrm{~W} / \mathrm{m}^{2 \circ} \mathrm{C}$, at the floor surface, the heat gain from the floor $\mathrm{Q}=\mathrm{h}\left(\mathrm{T}_{\text {floor }}-\mathrm{T}_{\text {air }}\right)=4 \mathrm{~W} / \mathrm{m}^{2}$. If $\mathrm{Q}$ is represented by the temperature difference between $T_{\text {control }}$ and $T_{\text {floor }}$, then $Q=h_{\text {corrected }}\left(T_{\text {floor }}-T_{\text {control }}\right)=h_{\text {corrected }}(20-24)=4 \mathrm{~W} / \mathrm{m}^{2}$, one would obtain $\mathrm{h}_{\text {corrected }}=-1 \mathrm{~W} / \mathrm{m}^{2}{ }^{\circ} \mathrm{C}$. It may even cause the singularity problem if $\mathrm{T}_{\text {control }}=20^{\circ} \mathrm{C}$.

Negative h may cause divergence and instability of an ES simulation. ES solves the following matrix equation for surface energy balance

$$
\mathbf{H} \cdot \mathbf{T}=\mathbf{q}
$$

where, 


$$
\mathbf{H}=\left[\begin{array}{cccc}
\mathrm{h}_{1, \mathrm{c}}+\sum_{\mathrm{k}=1}^{\mathrm{N}} \mathrm{h}_{1 \mathrm{k}, \mathrm{r}} & -\mathrm{h}_{12, \mathrm{r}} & \ldots & -\mathrm{h}_{1 \mathrm{~N}, \mathrm{r}} \\
-\mathrm{h}_{21, \mathrm{r}} & \mathrm{h}_{2, \mathrm{c}}+\sum_{\mathrm{k}=1}^{\mathrm{N}} \mathrm{h}_{2 \mathrm{k}, \mathrm{r}} & \ldots & -\mathrm{h}_{2 \mathrm{~N}, \mathrm{r}} \\
\ldots & \ldots & \ldots & \ldots \\
-\mathrm{h}_{\mathrm{N} 1, \mathrm{r}} & \ldots & -\mathrm{h}_{\mathrm{NN}-1, \mathrm{r}} & \mathrm{h}_{\mathrm{N}, \mathrm{c}}+\sum_{\mathrm{k}=1}^{\mathrm{N}} \mathrm{h}_{\mathrm{Nk}, \mathrm{r}}
\end{array}\right]
$$

$\mathbf{T}=\left[\begin{array}{c}\mathrm{T}_{1} \\ \mathrm{~T}_{2} \\ \cdots \\ \mathrm{T}_{\mathrm{N}}\end{array}\right]$

$$
\mathbf{q}=\left[\begin{array}{c}
\mathrm{q}_{1, \text { in }}+\mathrm{h}_{1, \mathrm{c}} \mathrm{T}_{\text {room }} \\
\mathrm{q}_{2, \text { in }}+\mathrm{h}_{2, \mathrm{c}} \mathrm{T}_{\text {room }} \\
\ldots \\
\mathrm{q}_{\mathrm{N}, \text { in }}+\mathrm{h}_{\mathrm{N}, \mathrm{c}} \mathrm{T}_{\text {room }}
\end{array}\right]
$$

and $T_{i}$ is the temperature of interior surface $i, h_{i, c}$ is the convective heat transfer coefficient of surface $i, h_{i j, r}$ is the radiative heat transfer coefficient between surface $i$ and surface $j, q_{i, \text { in }}$ is incoming heat to surface $i$ (e.g. the conductive heat through the envelopes), $\mathrm{N}$ is the total surface number.

Therefore,

\section{$\mathbf{T}=\mathbf{q} / \mathbf{H}$}

From matrix theory [19], $\mathbf{T}$ has a unique solution if only if $|\mathbf{H}| \neq 0$, i.e. $\mathbf{H}$ is nonsingular. $\mathbf{H}$ is singular if and only if the rank of $n \times n$ matrix $\mathbf{H}<\mathrm{n}$, which means that at least one row in $\mathbf{H}$ could be represented by the algebraic combination of the others. Due to the randomness of the coefficients in $\mathbf{H}$, it is impossible to anticipate the determinant of matrix $\mathbf{H}$ in general. However, the energy equation for each surface (each row in Equation (42)), although connected with other surfaces, cannot be determined by energy balances of the other surfaces. Therefore, matrix $\mathbf{H}$ is nonsingular, regardless of the sign of $h$.

When iteratively solving Equation (42) in ES, one may still meet the instability and divergence problems. Matrix theory [19] proves that the matrix should possess some properties to guarantee a converged solution. Following is a brief discussion on the issue with Jacobi method.

Equation (42) can be rewritten in the following manner

$$
\begin{aligned}
& {\left[\begin{array}{cccc}
1 & \mathrm{~h}_{1,2} / \mathrm{h}_{1,1} & \ldots & \mathrm{h}_{1, \mathrm{~N}} / \mathrm{h}_{1,1} \\
\mathrm{~h}_{2,1} / \mathrm{h}_{2,2} & 1 & \ldots & \mathrm{h}_{2, \mathrm{~N}} / \mathrm{h}_{2,2} \\
\ldots & \ldots & \ldots & \ldots \\
\mathrm{h}_{\mathrm{N}, 1} / \mathrm{h}_{\mathrm{N}, \mathrm{N}} & \ldots & \mathrm{h}_{\mathrm{N}, \mathrm{N}-1} / \mathrm{h}_{\mathrm{N}, \mathrm{N}} & 1
\end{array}\right]\left[\begin{array}{c}
\mathrm{T}_{1} \\
\mathrm{~T}_{2} \\
\ldots \\
\mathrm{T}_{\mathrm{N}}
\end{array}\right]=\left[\begin{array}{c}
\mathrm{q}_{1} / \mathrm{h}_{1,1} \\
\mathrm{q}_{2} / \mathrm{h}_{2,2} \\
\ldots \\
\mathrm{q}_{\mathrm{N}} / \mathrm{h}_{\mathrm{N}, \mathrm{N}}
\end{array}\right]} \\
& {\left[\begin{array}{c}
\mathrm{T}_{1} \\
\mathrm{~T}_{2} \\
\ldots \\
\mathrm{T}_{\mathrm{N}}
\end{array}\right]=\left[\begin{array}{c}
\mathrm{q}_{1} / \mathrm{h}_{1,1} \\
\mathrm{q}_{2} / \mathrm{h}_{2,2} \\
\ldots \\
\mathrm{q}_{\mathrm{N}} / \mathrm{h}_{\mathrm{N}, \mathrm{N}}
\end{array}\right]-\left[\begin{array}{cccc}
0 & \mathrm{~h}_{1,2} / \mathrm{h}_{1,1} & \ldots & \mathrm{h}_{1, \mathrm{~N}} / \mathrm{h}_{1,1} \\
\mathrm{~h}_{2,1} / \mathrm{h}_{2,2} & 0 & \ldots & \mathrm{h}_{2, \mathrm{~N}} / \mathrm{h}_{2,2} \\
\ldots & \ldots & \ldots & \ldots \\
\mathrm{h}_{\mathrm{N}, 1} / \mathrm{h}_{\mathrm{N}, \mathrm{N}} & \cdots & \mathrm{h}_{\mathrm{N}, \mathrm{N}-1} / \mathrm{h}_{\mathrm{N}, \mathrm{N}} & 0
\end{array}\right]\left[\begin{array}{c}
\mathrm{T}_{1} \\
\mathrm{~T}_{2} \\
\ldots \\
\mathrm{T}_{\mathrm{N}}
\end{array}\right]}
\end{aligned}
$$

By iteratively solving (48), one can obtain the solution with a prescribed accuracy. Assuming after the $\mathrm{m}^{\text {th }}$ iteration,

$$
\mathbf{T}_{\mathrm{m}}=\mathbf{q}^{\prime}-\mathbf{H}^{\prime} \mathbf{T}_{\mathrm{m}-1}
$$

And if $\mathbf{T}$ is the exact solution, i.e.

$$
\mathbf{T}=\mathbf{q}^{\prime}-\mathbf{H}^{\prime} \mathbf{T}
$$


It can be easily seen, upon subtraction, that

$$
\mathbf{T}_{\mathrm{m}}-\mathbf{T}=-\mathbf{H}^{\prime}\left(\mathbf{T}_{\mathrm{m}-1}-\mathbf{T}\right)=\mathbf{H}^{, 2}\left(\mathbf{T}_{\mathrm{m}-2}-\mathbf{T}\right)=(-1)^{\mathrm{m}} \mathbf{H}^{\prime \mathrm{m}}\left(\mathbf{T}_{0}-\mathbf{T}\right)
$$

Hence

$$
\lim _{\mathrm{m} \rightarrow \infty}\left(\mathrm{T}_{\mathrm{m}}-\mathrm{T}\right)=0 \text { if } \lim _{\mathrm{m} \rightarrow \infty} \mathbf{H}^{\mathrm{m}}=0
$$

In other words, a necessary and sufficient condition for the convergence of the Jacobi method is that $\mathbf{H}^{\mathrm{m}}$ tends to zero as $\mathrm{m}$ tends to infinite. Such a limit occurs if the spectral radius of $\mathbf{H}$ is less than unit. For the moment, a sufficient condition can be

$$
|\mathbf{H}|<1
$$

since

$$
\left|\mathbf{H}^{\mathrm{m}}\right| \leq|\mathbf{H}|^{\mathrm{m}}
$$

From matrix theory, a sufficient condition when $|\mathbf{H}|$ is less than unity is to satisfy the following condition

$$
\sum_{\substack{j=1 \\ j \neq i}}^{N}\left|\frac{h_{i, j}}{h_{i, i}}\right|<1, i=1,2, \ldots, N
$$

With positive h values, the elements in the matrix $\mathbf{H}$ of Equation (42) always satisfy

$$
\left|\mathrm{h}_{\mathrm{i}, \mathrm{c}}+\sum_{\mathrm{j}=1}^{\mathrm{N}} \mathrm{h}_{\mathrm{ij}, \mathrm{r}}\right|>\sum_{\substack{\mathrm{j}=1 \\ \mathrm{j} \neq \mathrm{i}}}^{\mathrm{N}}\left|-\mathrm{h}_{\mathrm{ij}, \mathrm{r}}\right|
$$

which makes $\mathbf{H}$ a diagonal dominant matrix, assuring that there exists a unique solution for the vector $\mathbf{T}$.

When $\mathrm{h}_{\mathrm{i}, \mathrm{c}}$ is negative, Equations (55) or (56) may not be satisfied, which could cause divergence and instability during a calculation. The divergence and instability may not always occur, since satisfying Equation (55) is only a sufficient condition. In general, the larger the real situation departs from Equation (55) (i.e. the larger negative $\mathrm{h}_{\mathrm{i}, \mathrm{c}}$ ), the higher the probability of divergence and instability.

\section{CONCLUSIONS}

In a coupled simulation of ES and CFD, CFD provides convective heat transfer on interior surfaces of building envelope to ES. Accurate prediction of the convective heat transfer by CFD is crucial to the accuracy of building energy calculation. The size of first grid to an interior surface and turbulence model in CFD are most important to the calculation of convective heat transfer. The convective heat transfer determined from the first grid cell, rather than from a prescribed location, should be used in the coupled simulation.

This investigation found that the calculated convective heat transfer depends on the size of first grids by analyzing laminar flows of forced and natural convection over a flat plate. The error of convective heat transfer due to the size of first grids (2D) is on the order of $\mathrm{O}\left(\mathrm{D}^{2}\right)$ for laminar forced convection and $\mathrm{O}(\mathrm{D})$ for natural convection.

This study further discussed the combined effect of the size of first grids and turbulence model on the convective heat transfer. Three zero-equation models have been used: the costant viscosity model, Xu's model, and the Prandtle mixing length model. A finer grid distribution in CFD does not always lead to a more accurate solution when the constant viscosity turbulence model is used or when the first grid is in the sub-layer boundary with the other zero-equation turbulence models. Based on the theoretical analysis and numerical experimentation, the study suggests a universal first grid size of $0.005 \mathrm{~m}$ for indoor natural convection airflows and $0.1 \mathrm{~m}$ for indoor forced convection airflows.

This investigation also found that the convective heat transfer coefficients, using traditional definition for building energy simulation, could become negative for room with strong temperature stratification, such as with displacement ventilation. The theoretical analysis shows that a negative convective heat transfer coefficient may cause divergence and instability in energy simulation. 


\section{REFERENCES}

1. Clarke J.A. Energy simulation in building design. Adam Hilger, Bristol, 1985.

2. Chen Q. Computational fluid dynamics for HVAC - successes and failures. ASHRAE Transactions 1997; 103(1): 178-187.

3. Martin P. CFD in the real world. ASHRAE Journal 1999; 1: 20-25.

4. Chen Q. and Srebic J. Application of CFD tools for indoor and outdoor environment design. Int. Journal on Architectural Science 2000; 1(1): 14-29.

5. Clarke J.A., Dempster W.M., and Negrao C.O.R. The implementation of a computational fluid dynamics algorithm within the ESP-r system. Proc. Building Simulation 1995, 166-175, Madison, USA, Int. Building Performance Simulation Association.

6. Nielsen P.V. and Tryggvason T. Computational fluid dynamics and building energy performance simulation. Proc. Roomvent 1998, 1, 101-107, Stockholm Sweden.

7. Srebric J., Chen Q., and Glicksman L.G. A coupled airflow-and-energy simulation program for indoor thermal environmental studies. ASHRAE Transactions 2000; 106(1): 465-476.

8. Beausoleil-Morrison I. et al. Further developments in the conflation of CFD and building simulation. Seventh International IBPSA Conference 2001 (BS2001), 2, 1265-1274, Rio de Janeiro, Brazil.

9. Zhai Z., Chen Q., Haves P. and Klems J.H. On approaches to couple energy simulation and computational fluid dynamics programs. Building and Environment 2002; 37: 857-864.

10. Patankar S.V. Numerical heat transfer and fluid flow. New York: Hemisphere/ McGraw-Hill, 1980.

11. Lienhard J. A heat transfer textbook (3rd edition). Massachusetts Institute of Technology, Cambridge, MA, 1999.

12. $\mathrm{Xu} \mathrm{W.} \mathrm{New} \mathrm{turbulence} \mathrm{models} \mathrm{for} \mathrm{indoor} \mathrm{airflow} \mathrm{simulation.} \mathrm{Ph.D.} \mathrm{Thesis,} \mathrm{Department} \mathrm{of} \mathrm{Architecture,}$ Massachusetts Institute of Technology, Cambridge, MA, 1998.

13. Prandtl L. Uber die ausgebildete turbulenz. ZAMM 1925; 5: 136-139.

14. Chen Q. Indoor airflow, air quality and energy consumption of buildings. Ph.D. Thesis, Delft University of Technology, The Netherlands, 1988.

15. Olson D.A., Glicksman L.R. and Ferm H.M. Steady-state natural convection in empty and partitioned enclosures at high Rayleigh numbers. ASME J. Heat Transfer, 1990; 112: 640-647.

16. Bohn M.S., Kirkpatrick A.T. and Olson D.A. Experimental study of three dimensional laminar convection at high Reyleigh number. ASME Journal of Heat Transfer 1984; 106: 339-345.

17. Fisher D.E. An experimental investigation of mixed convection heat transfer in a rectangular enclosure. Ph.D. Thesis, University of Illinois at Urbana-Champaign, USA, 1995.

18. Zhai Z. and Chen Q. Solution characters of iterative coupling between energy simulation and CFD programs. Energy and Buildings 2003; 35(5): 493-505.

19. Assem S.D. Advanced matrix theory for scientists and engineers, Abacus Press, Gordon and Breach Science Publishers, 1991. 
Figure 1 Illustration of the grid, cell, node, and distance to the surface in CFD

Figure 2 Laminar plate flows of forced and natural convection

Figure 3 Impact of turbulence model and first grid size on the error of convective heat transfer predicted by CFD

Figure 4 Configuration of the experiment [15]

Figure 5 Comparison of simulated heat transfer at enclosures with the data from [15]

Figure 6 Influence of first $\mathrm{CFD}$ grid size on the calculation of $\mathrm{Nu}$ at $\mathrm{Ra}=2.6 \times 10^{10}$

Figure 7 Schematic of experimental facility [17]

Figure 8 Comparison of simulated heat flux at enclosures with the measurement

Figure 9 Illustration of negative $\mathrm{h}$ 
(a)
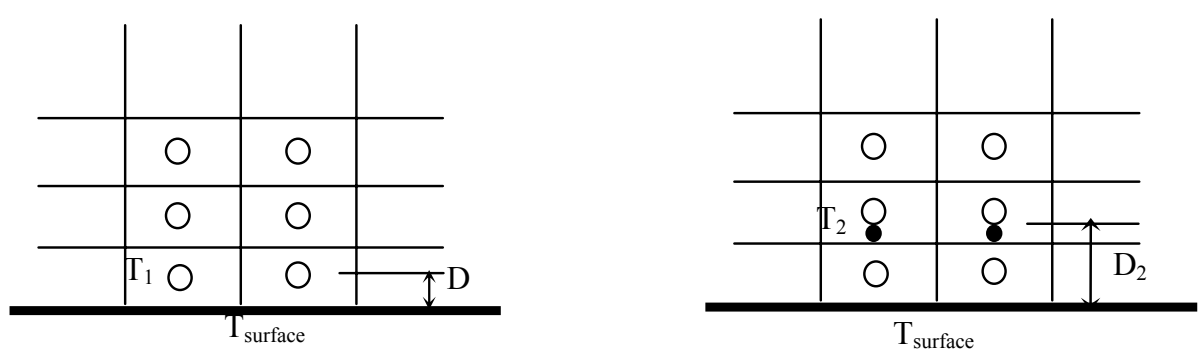

(b)

Figure 1 Illustration of the grid, cell, node, and distance to the surface in CFD 


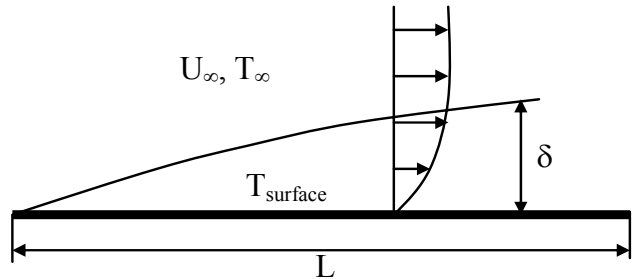

(a)

convection

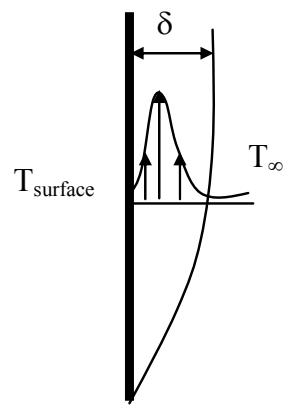

forced

(b) natural convection

Figure 2 Laminar plate flows of forced and natural convection 

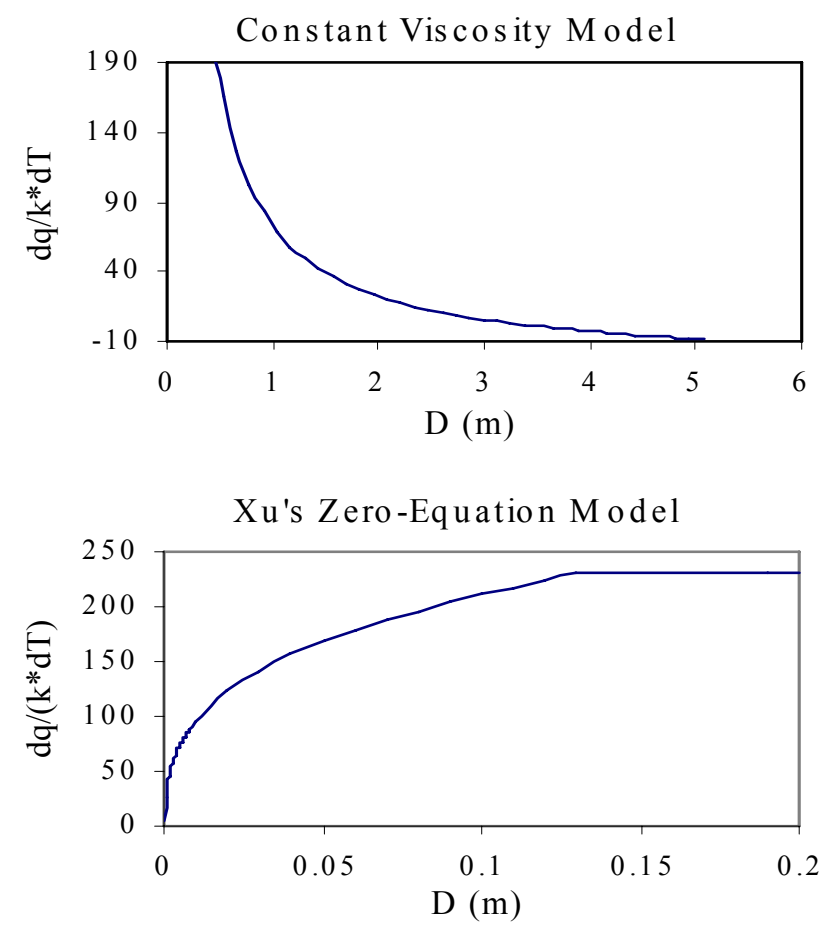

Figure 3 Impact of and first grid size on convective heat by CFD

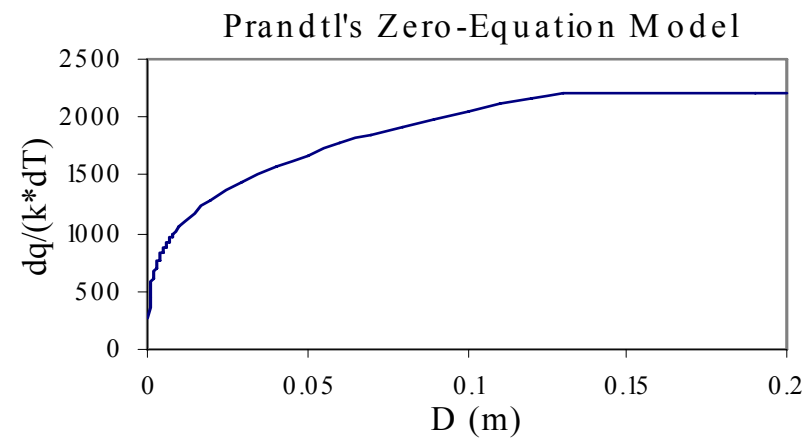

turbulence model the error of transfer predicted 


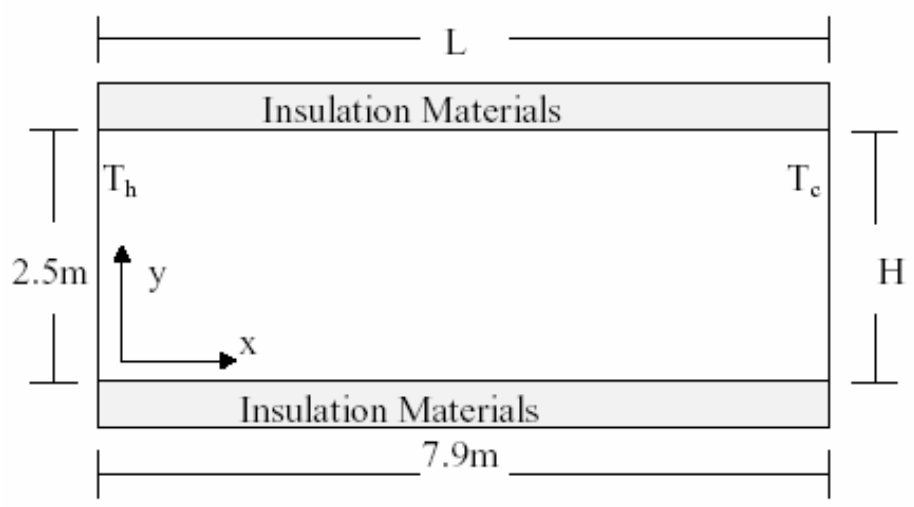

Figure 4 Configuration of the experiment (Olson et al. 1990) 


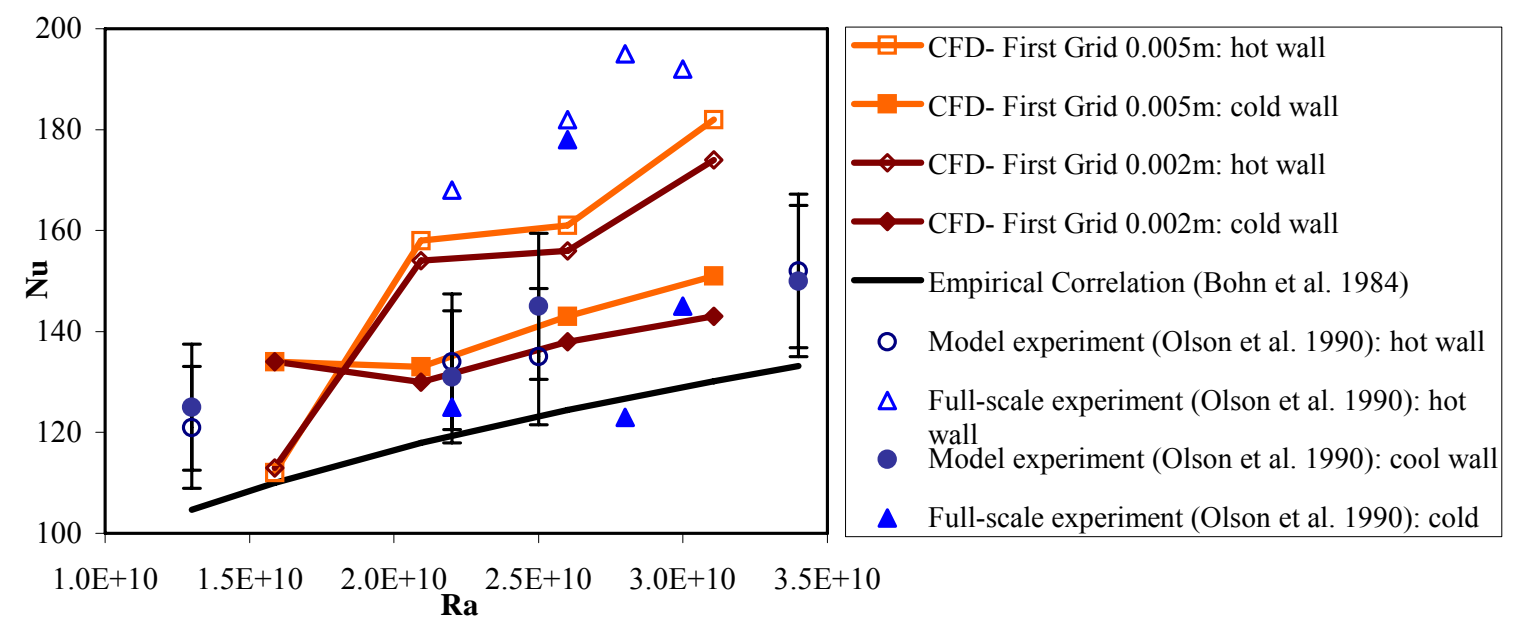

Figure 5 Comparison of simulated heat transfer at enclosures with the data from Olsen et al. (1990). 


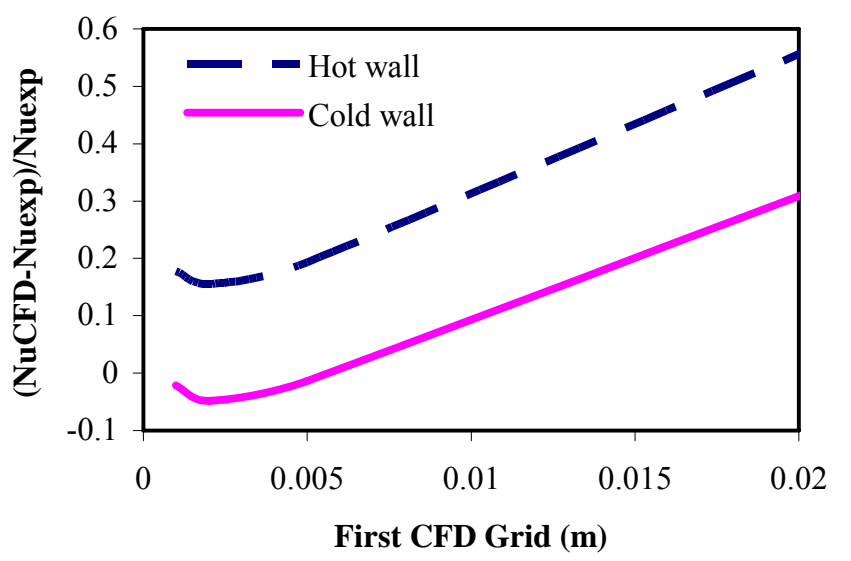

Figure 6 Influence of first CFD grid size on the calculation of $\mathrm{Nu}$ at $\mathrm{Ra}=2.6 \times 10^{10}$ 


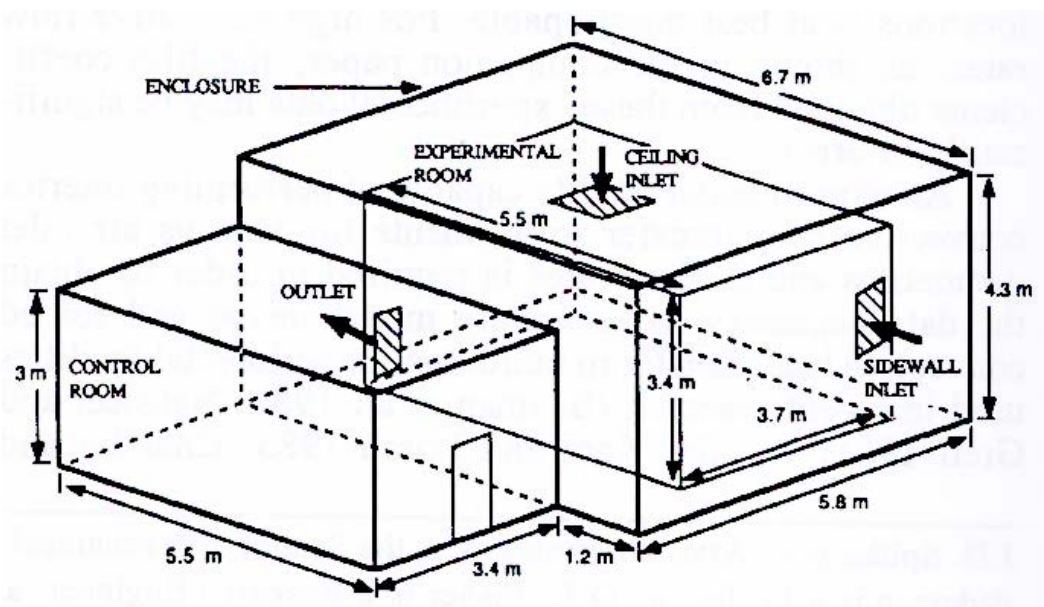

Figure 7 Schematic of experimental facility (Fisher 1995) 


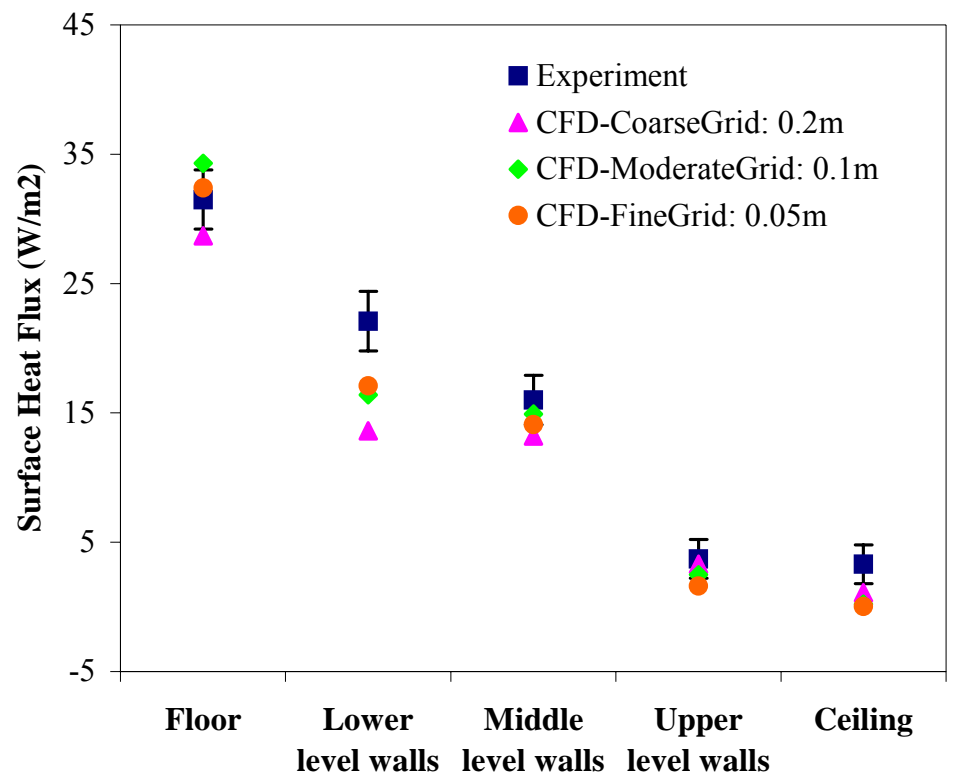

Figure 8 Comparison of simulated heat flux at enclosures with the measurement 


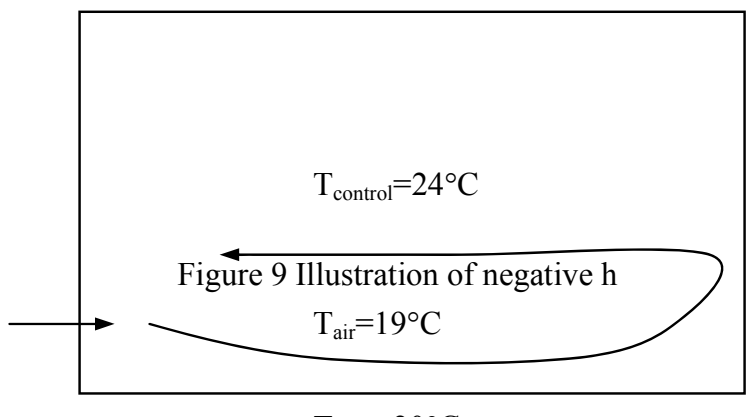

$\mathrm{T}_{\text {floor }}=20^{\circ} \mathrm{C}$ 